\title{
Developmental Links Between Trajectories of Physical Violence, Vandalism, Theft, and Alcohol-Drug Use from Childhood to Adolescence
}

\author{
Pol A. C. van Lier • Frank Vitaro • Edward D. Barker • \\ Hans M. Koot • Richard E. Tremblay
}

Published online: 17 December 2008

(C) The Author(s) 2008. This article is published with open access at Springerlink.com

\begin{abstract}
Differences in developmental trajectories of physical violence, vandalism, theft, and alcohol-drug use from ages 10 to 15 were studied. For females and for males, three trajectories of theft and of alcohol-drug use increased from 10 years to 15 years, while only the high trajectory of vandalism increased from ten to 14. All trajectories of physical violence decreased. Children who engaged in the
\end{abstract}

\author{
P. A. C. van Lier $(\bowtie) \cdot H$. M. Koot \\ Department of Developmental Psychology, \\ VU University Amsterdam, \\ Van der Boechorststraat 1, \\ 1081 BT Amsterdam, The Netherlands \\ e-mail: pac.van.lier@psy.vu.nl \\ F. Vitaro \\ Research Unit of Children's Psychosocial Maladjustment, \\ Université de Montréal, \\ Montréal, Canada \\ E. D. Barker \\ Center for Prevention of Youth Behavior Problems, \\ Department of Psychology, University of Alabama, \\ Tuscaloosa, AL, USA \\ E. D. Barker \\ SGDP Centre, Institute of Psychiatry, Kings College London, \\ London, UK \\ R. E. Tremblay \\ Departments of Pediatrics, Psychiatry, and Psychology, \\ Université de Montréal, Montréal, \\ Montréal, Canada

\section{R. E. Tremblay} \\ International Laboratory for Child \\ and Adolescent Mental Health Development, \\ INSERM U669, \\ Paris, France
}

high trajectories of vandalism, theft, and alcohol-drug use had a high probability of also being high in physical violence. Compared to males, females were less likely to be on the high trajectory of physical violence, and their trajectories of other antisocial behaviors were less strongly associated with high levels of physical violence. The results suggest that physical violence during pre-adolescence and adolescence has a different developmental pattern than other forms of antisocial behavior, and that its relation to these other forms of antisocial behavior differs by sex.

Keywords Physical violence - Vandalism - Theft .

Alcohol-drug use $\cdot$ Developmental trajectories

The childhood versus adolescent onset theory is widely embraced and describes the onset of antisocial behavior (ASB) among children and adolescents (Loeber and Stouthamer Loeber 1998; Moffitt 1993; Patterson et al. 1989; Patterson and Yoerger 1993, 1997). According to this theory, some children will be engaging in ASB early in life - at or before age 10 (American Psychiatric Association 1994) - and follow a life course persistent pathway of ASB. This onset pattern is rare, persistent, pathological and believed to occur primarily among males. Amongst other youth, however, the onset of antisocial behavior occurs in adolescence and is believed to be relatively more common, limited to adolescence and early adulthood, and with less gender disparity when compared to early onset pathway (Moffitt 1993). Moffitt and colleagues (Moffitt and Caspi 2001; Moffitt et al. 1996, 2002) used longitudinal data and identified youth following the childhood or the adolescent onset path of ASB. In accordance with the theory, these researchers showed that although $5-10 \%$ of children first engage in ASB in childhood, a considerably larger percentage starts in adolescence $(26 \%)$. Findings from other longitudinal studies were 
also in support of this theory (e.g., Fergusson and Horwood 2002; Hoeve et al. 2008; van Lier et al. 2007).

Despite support for a distinction based on the age of onset of ASB, it is important to note that some studies did not find both childhood and adolescent onset patterns paths (Chung et al. 2002; Fergusson et al. 2000; Wiesner and Capaldi 2003). One possible explanation of these contradictory results may be a methodological artefact that we refer to as 'lumping or splitting' (see Vitaro et al. 2006). Specifically, studies that supported the childhood vs. adolescent onset distinction often lumped different forms of ASB into a single score. Although the specific items differed across studies, the ASB scores in each study were comprised of various behaviors including oppositional behavior, physical aggression, vandalism, and property offenses (Fergusson and Horwood 2002; Moffitt et al. 1996, 2002; van Lier et al. 2007). These different behaviors, however, may have specific developmental courses (Barker et al. 2007; Tremblay 2003). Moreover, they may have unique underlying causes associated with their emergence and course over time. For example, we know that physical aggression is already present during the infancy-toddler period (Koot et al. 1997; NICHD Early Child Care Research Network 2004; Tremblay et al. 1996, 2004) and thereafter decreases from early childhood through adolescence (Côté et al. 2006; Tremblay 2006). Indeed, in a number of studies an adolescent onset pathway specific to physical aggression failed to be identified (Bongers et al. 2004; Brame et al. 2001; Nagin and Tremblay 1999). By contrast, behaviors such as vandalism, truancy, substance use and property offenses (such as stealing cars) become increasingly pronounced during adolescence (Barker et al. 2007; Bongers et al. 2004; Chassin et al. 2004; Chassin et al. 2002; Lacourse et al. 2002). Lumping different forms of antisocial behavior may therefore obstruct the study of domainspecific development of ASB and underlying mechanisms (Barker et al. 2007). Tremblay (2003) suggested the study of specific forms of ASB may enhance our understanding of the types of ASB emerging in childhood and the types that emerge in adolescence (see also Loeber and Hay 1997). The first aim of this study is to explore the developmental trajectories of physical violence, theft, vandalism, and alcoholdrug use from late childhood to middle adolescence (ages 1015 years), and to test whether all forms of antisocial problems have childhood as well as adolescent onset trajectories.

A second issue in regard to the age of onset of ASB pertains to the question of whether or not certain types of ASB evolve from other types (e.g., adolescent engagement in theft being preceded by childhood physical violence), and the likelihood of "de novo" onset of types of ASB. Moffitt's theory assumes a de novo onset of certain nonviolent forms of ASB among adolescent onset youths. Childhood onset is - according to the theory-associated with persistent behavioral difficulty in early childhood. However, this theory does not describe how different manifestations of ASBs develop once they have started. For the childhood onset group, it is likely that the manifestations of ASB change over time. As stated previously, studies have shown that physical aggression peaks in early childhood and declines thereafter for the majority of children (Archer and Côte 2005; Broidy et al. 2003; Côté et al. 2006; NICHD Early Child Care Research Network 2004). However children on a high trajectory of physical aggression throughout the elementary school years will use most other forms of antisocial behavior such as theft, and vandalism (Broidy et al. 2003; Côté et al. 2006; Nagin and Tremblay 1999), which typically increase in adolescence (Bongers et al. 2004). Therefore, and given the stability of ASB for early onset youth, it is unlikely that these individuals simply cease to be physically aggressive. Rather, these highly physically aggressive youth will likely engage in other types of ASB that are more salient in adolescence, such as high level vandalism, theft, and alcohol-drug use.

In contrast, adolescent onset youth are unlikely to be engaging in high levels of physical violence during adolescence, given that physical aggression normatively declines with age. However, and according to Moffitt (1993), these individuals are more likely to be engaging in non-violent forms of ASB (theft, vandalism, and drugalcohol). Hence, high levels of physical aggression should differentiate the two onsets. Although studies on the cooccurrence of forms of ASB are limited, support for this distinction is found. For instance, Barker et al. (2007) reported that many children who were high in physical violence - with already elevated levels behavior in late childhood-were likely to also engage in high levels of theft, which increased throughout adolescence. In contrast, only the minority of children who engaged in high levels of theft were also high in levels of physical violence. These results suggest that cases with a de novo onset of ASB are much more likely to engage in theft than in physical violence. Similar findings were reported by Loeber and colleagues (Loeber et al. 1993). These authors found that among those who engaged in deviant forms of covert ASB (e.g., theft, vandalism), $40 \%$ never engaged in serious forms of overt ASB (physical violence). Age may have been the decisive factor. That is, Loeber's study reported that older boys (mean age 13.4 years old) were more likely to engage in serious covert ASB than younger boys (mean age 10.2 years old). In contrast, younger boys were as likely to engage in serious overt ASB as older boys. Similar effects of age on the engagement in overt and covert ASBs have been reported in the National Youth Study (Elliott et al. 1985), and in the Chicago Youth Development Study (Tolan et al. 1997). The second purpose of this study was, therefore, to examine the trajectories of vandalism, theft 
and alcohol-drug use depended on physical aggression. Toward this end, the developmental courses of vandalism, theft, and alcohol-drug use were estimated conditional on the developmental trajectories of physical aggression.

In studying the developmental trajectories of physical violence, theft, vandalism, and alcohol-drug use we take into account possible sex differences. It is well established that high levels of ASBs are most prevalent in boys during childhood (Barker et al. 2007; Bongers et al. 2004; Broidy et al. 2003; Côté et al. 2006, 2007; Crick and Zahn-Waxler 2003; van Lier et al. 2005). However, such differences may diminish with age as Moffitt and colleagues (Moffitt et al. 2001) found that males and females are most alike in their level of ASB in mid-adolescence. Indeed Silverthorn and Frick (1999) argued that girls exclusively follow a 'delayed' adolescent onset path. However, as stated previously, physical aggression is high during childhood, whereas covert antisocial acts (vandalism \& theft) are more common during adolescence. Our third objective is therefore to explore whether males and females are equally distributed over the developmental trajectories, and whether the co-occurrence patterns between trajectories of specific forms of ASB differ between the sexes.

In summary, we aimed to study whether or not differences in the manifestation of ASB should be taken into account when trying to understand the distinction in age of onset of ASB. The first research goal was to explore the developmental trajectories of physical violence, theft, vandalism, and alcohol-drug use, and to test whether they follow similar or dissimilar developmental trajectories. We hypothesized that a high trajectory of physical violence would onset already in childhood, and would tend to decrease between 10 years and 15 years of age. In contrast, trajectories of vandalism, theft, and alcohol-drug use would have low levels in childhood (although some variation is expected), but would increase during adolescence. Given that we anticipate trajectories of physical violence to onset in childhood, we hypothesize that females are especially unlikely to follow a high physical violence trajectory (Fontaine et al. 2008; Moffitt et al. 2001; Silverthorn and Frick 1999). Our second goal was to study the cooccurrence between trajectories of physical violence, with theft, vandalism, and alcohol/drug use. We hypothesized that children who are high on physical violence already at age 10 years (i.e., early onset) are very likely to engage in a high trajectory of vandalism, theft, and alcohol/drug use. We expected that especially males will follow this (early onset) pattern. We also expect that high trajectories of vandalism, theft and alcohol-drug would not be exclusively followed by children who were also on the high trajectory of physical aggression. That is, we hypothesize that adolescent onset cases would follow high trajectories of vandalism, theft and alcohol/drug use, but not the high trajectory of physical violence.

\section{Method}

\section{Participants}

Participants in the present study were 360 Caucasian children (52\% boys) in which self-reported ASB was surveyed yearly from age 10 to age 15 (i.e., six data waves) in addition to teacher rated problem behavior from age 6 years to 10 years. All children lived in a small city in northwestern Quebec, Canada, and attended five different elementary schools (up to age 12), after which they transferred to one large high school (except for those who were retained). The schools were relatively homogeneous in size, number of classes, characteristics of the children in the classes, and characteristics of the neighborhood. In addition, all children attended regular classrooms, although $12 \%$ of the sample was in classrooms with younger classmates because of grade retention. In each year of data collection, at least $90 \%$ of children in the targeted classrooms participated in the study. Those who did not participate did not receive parental permission or were absent from school on the day of data collection.

Data used in this study come from a larger study of 455 children. Two criteria were used for inclusion in the present study. First, self-reported ASB scores at age 10 years had to be present to as an indication of ASB in childhood. DSMIV (American Psychiatric Association 1994) regards age 10 as the critical age to for childhood conduct disorder. Second, the child had to have participated in at least three of the six annual assessments. In total 95 participants were excluded by virtue of these two criteria, leading to the final sample of 360 participants (188 boys and 172 girls). No differences were present in gender distribution and grade retention between included and excluded children. The overall delinquency scores from age 10 years to 15 years were similar for included and excluded children. Participants' socioeconomic status (SES) was similar to the SES of a representative sample of 2,000 same age children throughout the Province of Quebec, according to the Blishen et al. (1987) occupational prestige scale ( $M=$ 43.15; $S D=13.12$ ). Parental permission was obtained each year for all participants. At age $10,73 \%$ of children lived in intact families with two biological parents, $11 \%$ lived in blended family households, $14 \%$ in single parent families (predominantly with their mothers), and $2 \%$ lived in other family configurations.

\section{Procedure}

Each spring, participants spent 2 hours of classroom time, divided by a 20 -min break, answering questionnaires. After the children were informed about the purpose of the study, they were told that all of their answers would be con- 
fidential and that they did not have to answer any of the questions if they did not want to. The children were encouraged to keep their answers confidential and not to talk with classmates about their answers. Trained research assistants administered and collected the questionnaires. Teachers were asked to leave the classroom during the assessment time to emphasize that participants' answers would not be revealed to their teachers.

From age 6 through age 10, the teachers completed the questionnaires during school time while research assistants took charge of the classroom to collect sociometric data (not reported here).

\section{Measures}

Participants' antisocial behaviors from age 10 through 15 were assessed by means of the Self-Reported Delinquency Questionnaire (SRDQ; LeBlanc and Fréchette 1989). At each assessment, the participants reported whether they had been involved in a variety of antisocial behaviors, such as physical violence (six items; e.g., Threaten to beat someone, Used a weapon, Beat someone without a reason, Engaged in a fistfight, Threw rocks or other objects at someone), vandalism (six items, e.g., Broken or destroyed something that did not belong to you, Demolishing school equipment, Having broken down part of a car deliberately, Setting fire), theft (ten items; e.g., Taken and kept something in a store without paying, Steals something from parents, Steals an amount of 10 Canadian dollars or more from school, Buying, using or selling something that has been stolen, Stealing by breaking and entering), or drugalcohol use (three items; Used marijuana, Binge drinking, Drinks alcohol) over the past 12 months. They indicated how frequently in the last year they had engaged in each act, with the following possible responses: $0=$ never, $1=$ rarely, 2 = sometimes, or $3=$ often. These scores were summed into the four ASB scales. Cronbach's alphas varied between 0.84 and $0.94,0.81$ and $0.90,0.82$ and 0.90 , and 0.77 and 0.86 from age 10 years through age 15 years for the physical violence, vandalism, theft, and alcohol-drug use scale, respectively. To explore whether each of these four ASB scales fitted a general ASB construct, confirmatory factor analyses were run at each time-point. CFIs ranged from 0.92-1.0, (with CFI in five of the six assessments $\geq 0.97$ ) indicating that at each assessment, ASB was well indicated by the four scales.

The 25 items of the SRDQ were embedded in various other items pertaining to school, hobbies, social relationships, and parent relationships. LeBlanc and McDuff (1991) reported satisfactory convergent validity with higher correlations among the subscales of the SRDQ $(r \sim 0.35)$ than with other scales tapping into family relationships and school $(r \sim 0.20)$. As for discriminant and predictive validity, the SRDQ scales significantly distinguished groups of adjudicated and non-adjudicated juveniles and distinguished adolescents who subsequently received a criminal record by age 30 years from those who remained without a crime record (see also Loeber and LeBlanc 1990). Other researchers have also documented the validity of selfreported measures of delinquency (Hindelang et al. 1981; Klein 1989).

Participant's physical aggression from age 6 to age 10 was annually rated by the teachers through the Social Behavior Questionnaire (SBQ; Loeber et al. 1989). The SBQ is a 32-item behavior-rating questionnaire in which teachers indicated whether items did not apply (0), applied sometimes (1), or applied often (2) to a target child. The physical aggression scale was comprised of four items including Gets into fights, and Physically attacks others. Raw mean scores were (with $S D$ 's in parentheses) 0.68 (1.26), 0.49 (1.07), 0.63, (1.29), 0.53 (1.12), and 0.36 (0.93) for ages 6-10 years respectively. The physical aggression scores were normalized through a square root transformation. Cronbach's alphas ranged from 0.80 to 0.87 from age 6 through age 10 .

\section{Statistical Approach}

The analyses were performed in two stages. First, the developmental trajectories of self-reported physical violence, vandalism, theft and alcohol-drug use were analyzed using Growth Mixture Modeling (GMM; Muthén and Shedden 1999; Nagin 1999). The objective of GMM is to find the smallest number of groups of individuals with similar developmental trajectories of ASB. The optimal number of trajectories was chosen via three criteria. The first was the relative fit of the models, through the Bayesian Information Criterion (BIC), the sample size adjusted BIC (aBIC), and the Lo-Mendell-Rubin Likelihood Ratio Test (LMR-LRT) (Kass and Raftery 1993; Nylund et al. 2007; Schwartz 1978). Lower BIC values indicate a more parsimonious model. LMR-LRT provides a $k-1$ likelihoodratio based method for determining the ideal number of trajectories; a low $\mathrm{p}$-value $(p<0.05)$ indicating a better fit to the data. Moreover, the entropy statistic, a measure of classification accuracy with values closer to 1 indexing greater precision (range 0 to 1 ) has to be above 0.70 (Nagin 2005). The second is the usefulness of the trajectories criterion (Muthén and Muthén 2000; Nagin 2005). Given our sample size, trajectories which were comprised of less than $5 \%$ of the sample were considered; in the trajectory models in which two forms of ASB were analyses simultaneously (see description below), smaller trajectory classes would make the proportion of children following certain transitions near zero. The third criterion is the stability of the different model solutions. For each model, 
100 random perturbations of starting values were generated by the program and the model was run for 20 iterations. The ending values from the ten optimizations with the highest log-likelihood were used as the starting values for the final-stage optimization. A model was considered stable when random perturbations of starting values were replicated.

The criteria for choosing the optimal number of trajectories were used in a hierarchical manner. That is, as long as the usefulness and stability criteria were met, the model with the lowest BIC value was considered the optimal solution. For type of ASB, a model with three growth parameters (intercept, linear and quadratic term), per trajectory, was specified. For the initial identification of the number of trajectories, the variances and covariances of the growth parameters were held equal to zero, and the (residual) variances of the observed delinquency scores were held equal across time and trajectories (see Muthén 2004; Muthén and Muthén 1998). We then allowed these parameters to freely vary across trajectories (and time), to examine whether or not additional parameters improved model fit. The distributions of the selfreported ASB scores were non-normal, with the largest proportion of the sample exhibiting none of the problem behaviors. To accommodate this censoring problem, we modeled the developmental trajectories using a censored normal distribution.

In the second stage of the analyses, the co-occurrence between optimal solutions on physical violence and vandalism, theft, and alcohol-drug use was analyzed. The final trajectory models from the first stage served as the starting point. Three growth mixture models were used to estimate the co-occurrence patterns, in which physical violence was combined with the other outcome variables (vandalism, theft, alcohol-drug use, respectively). In each of these models, the trajectories of vandalism, theft and alcohol-drug use were regressed on the trajectories of physical violence to estimate the co-occurrence between each of the trajectory classes.

To test whether children on a high ASB trajectory from age 10 years to 15 years were already characterized by high level problem behaviors from age 6 years onwards (i.e., to make a claim of early onset plausible), the predictive link of age 6-10 years physical aggression to the trajectories of ASB from age 10 years to 15 years was estimated. A growth model, in which the population variance in initial level (age 6 years) and growth with age (6-10 years) in physical aggression was modeled using an intercept and linear growth parameter. These growth parameters were used to predict high trajectory of physical violence, vandalism, theft and alcohol-drug use, and were expressed as odds ratios. All analyses were performed with Mplus 4.21 (Muthén \& Muthén 2007).

\section{Results}

Trajectories of Physical Violence, Vandalism, Theft, and Alcohol-Drug Use

For the first research question, we examined the developmental trajectories of self-reported physical violence, vandalism, theft, and alcohol-drug use. The means of the self-reports for males and females are in Table 1. For each of our four ASBs, a model with three growth parameters (intercept, linear and quadratic term) was specified. Based on the criteria for deciding the optimal number of developmental trajectories (Table 2), three trajectories of physical violence, vandalism, and theft were identified as the best fit to the data. The additional trajectories resulted in either unstable solutions, non-converging solutions or in trajectory classes comprised of very few subjects $(<5 \%)$. For alcohol-drug use, up to six trajectories could be determined. However, the five-class solution yielded a trajectory with few subjects $(<5 \%)$ and the six class solution was unstable. The four-class solution was therefore chosen as the optimal one.

After determining the number of trajectories, we tested whether model fit could be improved. First we freed the variances of the growth parameters in the overall model, but constrained them to be equal over the trajectories. Second, we allowed the variances of the growth parameters to be different for the trajectories. Both strategies resulted in unstable and non-converging solutions. Third, we allowed trajectory specific (residual) variances for the observed ASB scores, across time. This improved model fit for physical violence, vandalism, and theft. Specifically, for physical violence, the optimal solution had trajectoryspecific variance for the observed scores in the high physical violence trajectory $(\mathrm{BIC}=5,433, \mathrm{aBIC}=5,391$, entropy $=0.74$; all ten final-stage models had identical solutions). The optimal vandalism solution had time specific residual variances of the observed scores in the overall model (i.e., variances were equal between trajectories but estimated for each time-point; $\mathrm{BIC}=4,443$, $\mathrm{aBIC}=$ 4,389 , entropy $=0.71$; all models replicated). The optimal theft solution had trajectory specific variance in the high theft trajectory $(\mathrm{BIC}=5,828, \mathrm{aBIC}=5,787$, entropy $=0.74$; all models replicated). Allowing for trajectory specific residual variances did not improve model fit for alcoholdrug use (entropy=0.79). The developmental trajectories for physical violence, vandalism, theft, and alcohol-drug use, and the percentage of children in each trajectory are shown in Fig. 1. The growth parameter estimates of the models are in "Appendix".

Physical Violence Of all children, 15.6\% followed a high developmental trajectory of physical violence from ages 

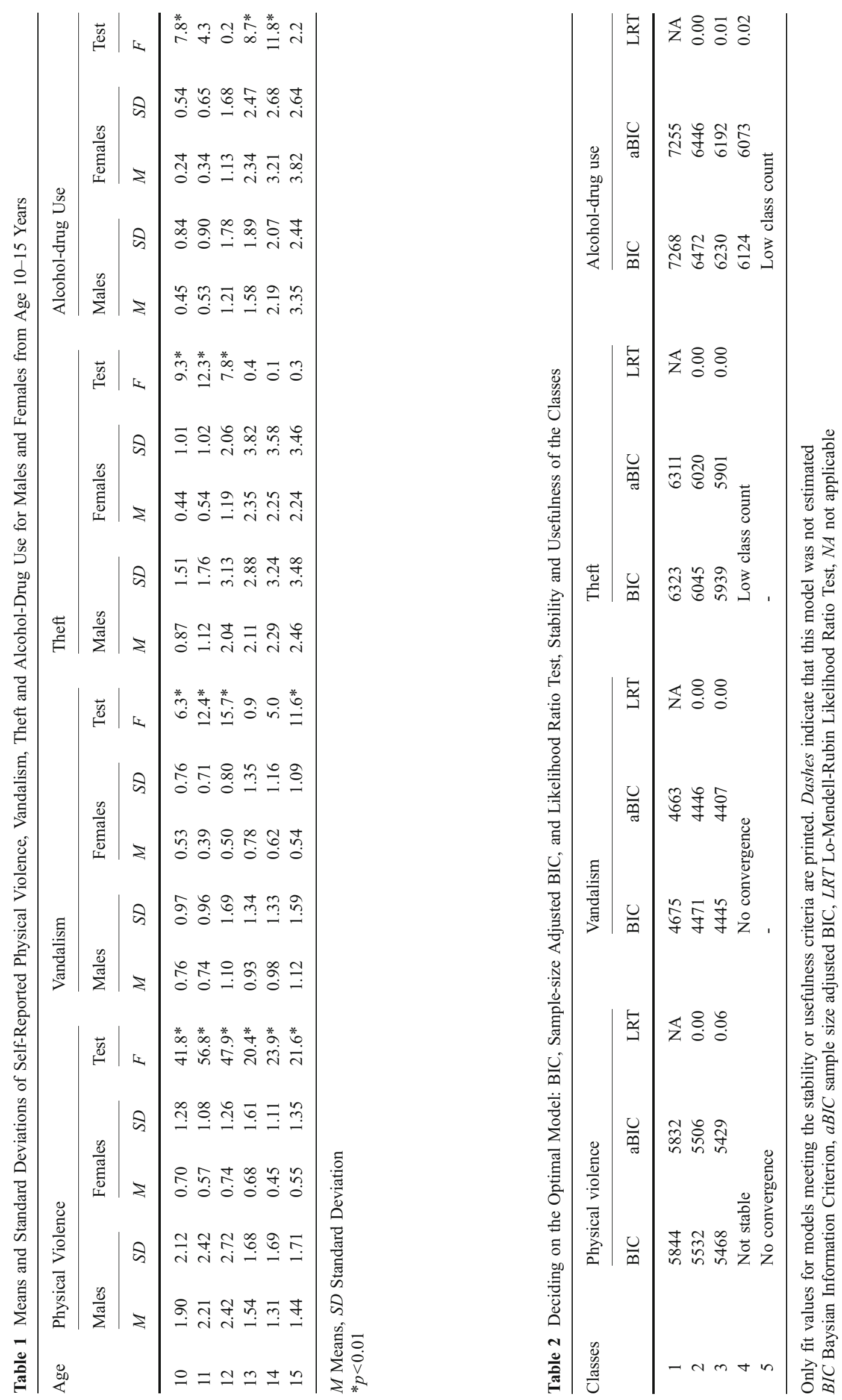

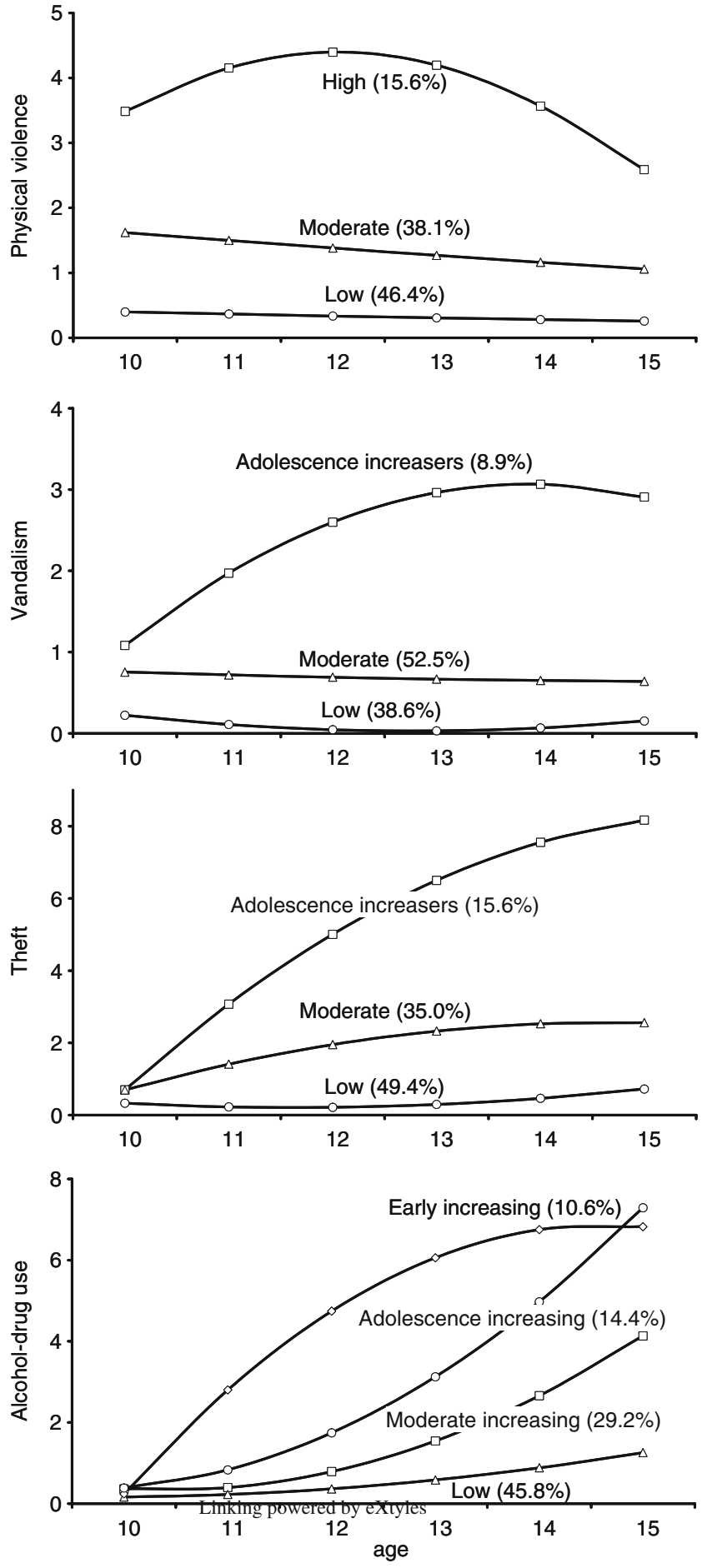

Fig. 1 Developmental trajectories of physical violence, vandalism, theft, and alcohol-drug use

10 years to 15 years old. Approximately $38 \%$ of the children followed a trajectory with stable moderate levels of physical violence. The remaining children, $46 \%$ of the total sample followed a low trajectory. Table 3 gives the odds ratios for males of being in the high and intermediate trajectories, as compared to females. The low physical violence trajectory is used as reference category. Males had a higher probability than females of following the high and intermediate trajectories.

Vandalism As expected, the three vandalism trajectories began with low levels at age 10 . However, $8.9 \%$ of the total sample reported increasing levels of vandalism during adolescence, which peaked at about age 14. Children who followed the two remaining developmental trajectories all had stable moderate $(52.5 \%)$ or low to absent $(38.6 \%)$ levels of vandalism. Males had a higher probability than female of following the high and intermediate vandalism trajectories (Table 3)

Theft All theft trajectories began with low levels at age 10 . However, $15.6 \%$ of the children reported increasing levels of theft through age 15 . The remaining two theft trajectories had slightly increasing but overall moderate levels of theft (35\% of the sample) or stable low levels of theft $(49.4 \%$ of the sample). Boys were more likely to follow the moderate theft trajectory (Table 3).

Alcohol-Drug Use Likewise to vandalism and theft, the alcohol-drug use trajectories had low to absent levels at age 10. All developmental trajectories showed increasing levels of alcohol-drug use with age. However, $10.6 \%$ of the sample already showed increasing levels of alcohol-drug use in late childhood and were among the highest users at age 15. An additional $14.4 \%$ started later, in early adolescence, but had similar levels of alcohol-drug use at age 15 years as youths who followed the early increasing path. The remaining children followed the moderate path (29.2\% of the sample) or low path (remaining $45.8 \%$ ).

Table 3 Male Gender and Trajectories of Physical Violence, Vandalism, Theft, and Alcohol/Drug use

\begin{tabular}{llr}
\hline & OR & \multicolumn{1}{c}{$95 \%$ CI } \\
\hline $\begin{array}{l}\text { Physical violence } \\
\text { High }\end{array}$ & $18.84^{* *}$ & $9.83-36.12$ \\
$\quad$ Moderate & $20.11^{* *}$ & $17.74-22.79$ \\
Vandalism & & \\
Adolescent increasers & $4.74^{* *}$ & $3.26-6.89$ \\
$\quad$ Moderate & $3.08^{* *}$ & $2.72-3.49$ \\
Theft & & \\
Adolescent increasers & 1.48 & $0.75-2.88$ \\
Moderate & $2.72^{*}$ & $1.47-5.05$ \\
Alcohol/Drug use & & \\
Childhood increasers & 0.43 & $0.18-1.02$ \\
Adolescent increasers & 0.47 & $0.19-1.13$ \\
Moderate & 0.82 & $0.43-1.57$ \\
\hline
\end{tabular}

The low trajectories served as reference category

$O R$ Odds Ratio, $C I$ Confidence Interval

${ }^{*} p<0.01 ;{ }^{*} p<0.05$ 
Males and females were equally likely to follow each of the alcohol-drug use trajectories (see Table 3).

In summary, for each type of ASB and alcohol-drug use, approximately $9-15 \%$ of children followed a high trajectory from late childhood into adolescence. However, for physical violence, children on the high trajectory already had high levels of such problems at age 10. This is in contrast to vandalism, theft, and alcohol-drug use, where all trajectories, even the most high, were nevertheless low in mean levels of these behaviors at age 10 years and peaked later in adolescence. That is, physical violence tended to decrease into middle adolescence, even for the high trajectory, whereas children on the high theft, vandalism, and alcohol-drug use trajectories showed increases in such behaviors.

Children with already high levels of ASB at age 10 years primarily exhibited physically violent acts. We therefore tested whether children on the high physical violence trajectory were already high on physical aggression in childhood, as an indication of persistent problems from childhood onwards. To test this, the growth parameters of physical aggression (intercept, slope) were used to predict high physical violence class membership. Because males had higher levels of physical aggression from age 610 years $\left(\beta_{\text {intercept }}=0.45, p<0.05\right)$, we controlled for sex in the growth parameters. Results showed that compared to children in the low physical violence trajectory, the intercept (level) of physical aggression from age 6 years to 10 years significantly increased the likelihood of following the high physical violence trajectory $(\mathrm{OR}=4.30$, 95\% CI $=1.03-17.94)$. We then tested whether childhood physical aggression predicted trajectories of vandalism, theft, and, alcohol drug use. The low trajectories always served as the reference category. No significant links were found.

Co-occurrence Between Developmental Trajectories of Physical Violence and Trajectories of Vandalism, Theft, and Alcohol-Drug Use

To address the second research question, we examined the co-occurrence patterns of physical violence with vandalism, theft, and alcohol-drug use.

Vandalism and Physical Violence The co-occurrence of the trajectories of physical violence and the other trajectories are presented in Table 4. Children who followed the adolescent increasing trajectory of vandalism almost all followed the high physical violence trajectory. No sex difference was found $(\mathrm{OR}=4.5, \mathrm{CI}=0.5-34.9)$.

Theft and Physical Violence The majority of the children who followed the adolescent increasers theft trajectory also
Table 4 Co-occurrence between Developmental Trajectories of Physical Violence and Developmental Trajectories of Vandalism, Theft, and Alcohol-Drug Use

\begin{tabular}{lrrr}
\hline Other trajectories & \multicolumn{3}{c}{ Physical Violence Trajectories } \\
\cline { 2 - 4 } & High & Moderate & Low \\
\hline Vandalism & & & \\
Adolescence increasing & 91.3 & 8.7 & 0.0 \\
Moderate & 4.6 & 82.1 & 13.3 \\
Low & 4.3 & 14.9 & 80.9 \\
Theft & & & \\
Adolescence increasing & 56.3 & 43.8 & 0.0 \\
Moderate & 17.1 & 78.6 & 4.3 \\
Low & 0.6 & 30.8 & 68.6 \\
Alcohol-drug use & & & \\
Early increasing & 45.9 & 54.1 & 0.0 \\
Adolescence increasing & 22.4 & 40.8 & 36.7 \\
Moderate increasing & 12.8 & 61.6 & 25.6 \\
Low & 3.4 & 26.8 & 69.8 \\
\hline
\end{tabular}

Entries reflect joint class percentages of trajectories of physical violence, with trajectories of vandalism, theft, and alcohol-drug use

followed the high physical violence trajectory $(56.3 \%$, see Table 4). However, males on the high physical violence trajectory had a higher probability than females to also follow the adolescent increasing theft trajectory $(\mathrm{OR}=7.1$, $\mathrm{CI}=2.0-25.7)$.

Alcohol-Drug Use and Physical Violence Less than half of the children who followed the early increasing high alcohol-drug use trajectory also followed the high physical violence trajectory $(45.9 \%$, see Table 4$)$. Males were more likely than females to follow this developmental pattern $(\mathrm{OR}=7.3, \mathrm{CI}=1.7-32.2$. No children in the early increasing trajectory followed the low physical violence trajectory.

In summary, significant co-occurrences were found between physical violence and theft, vandalism, and alcoholdrug use. This pattern of co-occurrence was especially high for physical violence and vandalism (91\%). Nevertheless, approximately $50 \%$ of the children on the high physical violence path also engaged in high level theft and alcoholdrug use from age 10 years to 15 years.

\section{Discussion}

The first question of this study was whether all forms of ASB develop in approximately identical ways. The second concerned the co-occurrence between forms of ASB. We also examined potential sex-differences in both the likelihood of following a high trajectory and in the cooccurrence between high trajectories. As we found that the sex of the child was related to both the level and course 
of ASB and to the co-occurrence between forms of ASB, we will address our results and their implications for understanding ASB development taking into account these sex differences.

\section{ASB Development}

Approximately $16 \%$ of the children followed a high physical violence trajectory. Children on this trajectory were likely to also have physical aggression problems in childhood. As expected, females were less likely than males to follow the high physical violence trajectory, in addition to, on average, being less physically aggressive from age 6 onwards. These findings support previous research on physical aggression (Bongers et al. 2004; Côté et al. 2006; NICHD 2004) and may suggest that girls learn more rapidly than boys to control their use of physical aggression and learn to express conflict in more socially acceptable manners (Côté et al. 2007; NICHD 2004; Tremblay 2003).

In contrast to physical violence, trajectories of vandalism, theft, and alcohol-drug use were characterized by, on average, low levels at age 10, but increasing levels into adolescence, which supported previous research (Bongers et al. 2004; Chassin et al. 2004; Chassin et al. 2002; Lacourse et al. 2002). We also expected and found that males were more likely than females to follow the high vandalism trajectory, whereas no sex-differences were identified in the high theft and alcohol-drug use trajectories. This suggests that females engage in approximately similar levels of non-violent ASB as their male counterparts, and is in accordance with previous findings on the diminishing sex-differences in adolescence (Moffitt et al. 2001).

The differences in the developmental courses of physical violence and the other forms of ASB (vandalism, theft and alcohol drug use) are inconsistent with the assumption that all forms of ASB develop in an identical way. They also appear to contradict the idea that there are early and late onset paths for all forms of ASB. Early onset appears to be specific to physical aggression (i.e., by age 10), while late onsets appears to characterize children who primarily engage in theft, vandalism, and alcohol-drug use. Hence, onset of physical violence is not typical of adolescence, as suggested by the World Health Organization report on violence and health (Krug et al. 2002), and by recent reports on youth violence from the Surgeon General of the US and the NIH (see Tremblay 2006).

Co-occurrence Between Physical Violence, Vandalism, Theft and Alcohol-Drug Use

Children on the high physical violence trajectory had high probabilities of also being on the high level vandalism, and to a slightly lesser extent, high level theft and alcohol-drug use trajectories. Moreover, none of the children who followed a high level trajectory of vandalism, theft, or alcohol-drug use followed the low physical violence trajectory. This suggests that adolescents who engaged in frequent non violent forms of ASB are likely to have engaged in physical violence (either high or moderate physical violence trajectory), during childhood and early adolescence.

The pattern of high physical violence trajectory with high level theft, vandalism, and alcohol-drug trajectories was especially observed among males. As stated previously, youth following the high physical violence trajectory were already highly physically aggressive in childhood (see also Côté et al. 2006; NICHD 2004; Nagin and Tremblay 1999). Thus, early onset cases, who are likely males, engage in high levels of all types of ASB. Adolescent onset cases, conversely, showed less gender disparity in non-aggressive antisocial acts, which were not predicted by childhood physical aggression. This suggests that in order to understand the development of antisocial behavior, we need to consider the development of specific forms of antisocial behavior, and their gender specific co-occurrence from early childhood to adolescence.

It is important to note that not all children in the physical violent trajectory were also in the high theft, vandalism and alcohol-dug use trajectories. To understand what factors protect the children with a history of physical aggression from frequent theft and alcohol-drug use we will need to take into account individual characteristics, such as cognitive functioning (Barker et al. 2007), and environmental circumstances, such as peer influences (Lacourse et al. 2006; Moffitt 1993; Patterson et al. 2000). Such factors may also explain why some children who were not high on physical violence do engage in the deviant theft and alcohol/drug use trajectories.

\section{Limitations}

Our first limitation regards the sample and age range studied. The sample was comprised of Caucasian youths from a small town in the Canadian province of Quebec. As such it was not a representative sample of the general population, and our findings may not generalize to specific risk populations. In addition, with a total of 360 children, the deviant trajectories were comprised of relatively small numbers of youths, especially among females. Consequently, the power in the estimation of the co-occurrence between the deviant trajectories was higher for males than for females. An alternative for exploring sex-differences in the developmental trajectories would have been to estimate the developmental trajectories for boys and girls separately. However, this would have drastically reduced the power to identify growth trajectories. The age range of the self-reported delinquency data was $10-15$ years of age. To fully understand the 
development of ASB data from early childhood to adulthood is required. For instance, previous studies have shown that physical aggression trajectories have their highest peaks in early childhood (Côté et al. 2007; NICHD 2004). This may also be the case for other forms of ASB, such as stealing (e.g., taking away things from others) and vandalism (e.g., destroying others toys). In addition, the highest levels of some forms of delinquent acts may not be at their peak at age 15 (White et al. 2001). Our results should thus be taken with reserve until they are replicated in larger and more diverse samples.

Second, GMMs have been criticized; this method can result in the detection of trajectory classes that are not present in the data (Bauer 2007). One way of minimizing this risk is to not use GMM in an exploratory manner, but rather to specify specific a priori hypotheses based on prior research regarding the shape of the trajectories and the relationship between trajectory membership and covariates (Muthén 2004). The shape of our trajectories and the relationship between following particular trajectories, and co-occurrence patterns with (male) sex were in accordance with our hypotheses.

Third, although our results underscore the importance of physical violence in the pathway to adolescent forms of ASB, it does not imply a causal link. Other, individual or contextual factors (e.g., genes, temperament, family characteristics, peers) may account for both the early development of physical violence and the later use of other forms of ASB. Fourth, all results were based on self-reports. The use of additional informants would have provided a more thorough picture of the antisocial behaviors exhibited in this sample.

Taken together, the results of this study and previous studies on the development of specific forms of ASB suggest that in order to understand the development of $\mathrm{ASB}$, the onset, the course, and the (time varying) consequences of all forms of $\mathrm{ASB}$, in addition to the patterns of co-occurrence needs to be studied from early childhood onwards. For each of these, sex differences should be taken into account to ensure that our knowledge can be generalized to both males and females.

Open Access This article is distributed under the terms of the Creative Commons Attribution Noncommercial License which permits any noncommercial use, distribution, and reproduction in any medium, provided the original author(s) and source are credited.

\section{Appendix}

Table 5 Growth Factor Means and Standard Errors of Trajectories of Physical Violence, Vandalism, Theft, and Substance Use From Age 10 Years to 15 Years

\begin{tabular}{|c|c|c|c|c|c|c|}
\hline & \multicolumn{2}{|l|}{ Intercept } & \multicolumn{2}{|c|}{ Linear slope } & \multicolumn{2}{|c|}{ Quadratic slope } \\
\hline & Estimate & $S E$ & Estimate & $S E$ & Estimate & $S E$ \\
\hline \multicolumn{7}{|l|}{ Physical violence } \\
\hline High & 3.457 & 0.574 & 0.972 & 0.507 & -0.243 & 0.105 \\
\hline Moderate & 1.176 & 0.296 & 0.070 & 0.201 & -0.041 & 0.043 \\
\hline Low & -1.300 & 0.334 & -0.492 & 0.247 & 0.068 & 0.053 \\
\hline \multicolumn{7}{|l|}{ Vandalism } \\
\hline Adolescent increasers & 0.808 & 0.298 & 1.190 & 0.369 & -0.158 & 0.074 \\
\hline Moderate & 0.172 & 0.179 & 0.141 & 0.181 & -0.029 & 0.039 \\
\hline Low & -1.297 & 0.268 & -0.860 & 0.479 & 0.106 & 0.098 \\
\hline \multicolumn{7}{|l|}{ Theft } \\
\hline Adolescent increasers & -1.737 & 0.834 & 3.644 & 0.633 & -0.332 & 0.131 \\
\hline Moderate & -0.441 & 0.336 & 1.443 & 0.241 & -0.184 & 0.052 \\
\hline Low & -1.733 & 0.305 & -0.218 & 0.294 & 0.079 & 0.057 \\
\hline \multicolumn{7}{|l|}{ Substance use } \\
\hline Childhood increasers & 0.241 & 0.191 & 2.874 & 0.268 & -0.311 & 0.069 \\
\hline Adolescent increasers & 0.386 & 0.139 & 0.212 & 0.190 & 0.234 & 0.041 \\
\hline Moderate & 0.363 & 0.061 & -0.146 & 0.106 & 0.180 & 0.025 \\
\hline Low & 0.162 & 0.034 & 0.023 & 0.047 & 0.039 & 0.012 \\
\hline
\end{tabular}

A censored normal distribution assumption was used in the estimation of the GMM models for physical violence, vandalism, and theft. As a consequence estimates of for instance the intercept, does not represent (by approximation) observed means at age 10 years SE Standard Error 


\section{References}

American Psychiatric Association. (1994). Diagnostic and statistical manual of mental disorders, Fourth edition. Washington, DC: American Psychiatric Association.

Archer, J., \& Côte, S. (2005). Sex differences in aggressive behavior: A developmental and evolutionary perspective. In R. E. Tremblay, W. W. Hartup, \& J. Archer (Eds.), Developmental origins of aggression (pp. 425-443). New York, NY: The Guilford.

Barker, E. D., Seguin, J. R., White, H. R., Bates, M. E., Lacourse, E., Carbonneau, R., et al. (2007). Developmental trajectories of violence and theft: relation to neurocognitive performance. Archives of General Psychiatry, 64, 592-599. doi:10.1001/ archpsyc.64.5.592.

Bauer, D. J. (2007). Observations on the use of growth mixture models in psychological research. Multivariate Behavioral Research, 42(4), 757-786. doi:10.1080/00273170701710338.

Blishen, B. R., Carroll, W. K., \& Moore, C. (1987). The 1981 socioeconomic index for occupations in Canada. The Canadian Review of Sociology and Anthropology. La Revue Canadienne de Sociologie et d'Anthropologie, 24, 465-488.

Bongers, I. L., Koot, H. M., Van Der Ende, J., \& Verhulst, F. C. (2004). Developmental trajectories of externalizing behaviors in childhood and adolescence. Child Development, 75, 1523-1537. doi:10.1111/j.1467-8624.2004.00755.x.

Brame, B., Nagin, D. S., \& Tremblay, R. E. (2001). Developmental trajectories of physical aggression from school entry to late adolescence. Journal of Child Psychology and Psychiatry, and Allied Disciplines, 42, 503-512. doi:10.1017/S0021963001007120.

Broidy, L. M., Nagin, D. S., Tremblay, R. E., Bates, J. E., Brame, B., Dodge, K. A., et al. (2003). Developmental trajectories of childhood disruptive behaviors and adolescent delinquency: a six-site, cross-national study. Developmental Psychology, 39, 222-245. doi:10.1037/0012-1649.39.2.222.

Chassin, L., Pitts, S. C., \& Prost, J. (2002). Binge drinking trajectories from adolescence to emerging adulthood in a high-risk sample: predictors and substance abuse outcomes. Journal of Consulting and Clinical Psychology, 70, 67-78. doi:10.1037/0022-006X.70.1.67.

Chassin, L., Fora, D. B., \& King, K. M. (2004). Trajectories of alcohol and drug use and dependence from adolescence to adulthood: the effects of familial alcoholism and personality. Journal of Abnormal Psychology, 113, 483-498. doi:10.1037/ 0021-843X.113.4.483.

Chung, I. J., Hill, K. G., Hawkins, J. D., Gilchrist, L. D., \& Nagin, D. S. (2002). Childhood predictors of offense trajectories. Journal of Research in Crime and Delinquency, 39, 60-90.

Côté, S., Vaillancourt, T., Leblanc, J. C., Nagin, D. S., \& Tremblay, R. E. (2006). The development of physical aggression from toddlerhood to pre-adolescence: a nation wide longitudinal study. Journal of Abnormal Child Psychology, 34, 71-85. doi:10.1007/ s10802-005-9001-z.

Côté, S., Vaillancourt, T., Barker, T., Nagin, D. S., \& Tremblay, R. E. (2007). The joint development of physical and indirect aggression: predictors of continuity and change during childhood. Development and Psychopathology, 19, 37-55. doi:10.1017/ S0954579407070034.

Crick, N. R., \& Zahn-Waxler, C. (2003). The development of psychopathology in females and males: current progress and future challenges. Development and Psychopathology, 15, 719742. doi:10.1017/S095457940300035X.

Elliott, D. S., Huizinga, D., \& Ageton, S. S. (1985). Explaining delinquency and drug use. Beverly Hills CA: Sage.

Fergusson, D. M., \& Horwood, L. J. (2002). Male and female offending trajectories. Development and Psychopathology, 14, 159-177. doi:10.1017/S0954579402001098.
Fergusson, D. M., Horwood, J. L., \& Nagin, D. S. (2000). Offending trajectories in a New Zealand birth cohort. Criminology, 38, 525551. doi:10.1111/j.1745-9125.2000.tb00898.x.

Fontaine, N., Carbonneau, R., Vitaro, F., Barker, E. D., \& Tremblay, R. E. (2008). A critical review of studies on the developmental trajectories of antisocial behavior in females. Journal of Child Psychology and Psychiatry, and Allied Disciplines. In press.

Hindelang, M. J., Hirschi, T., \& Weiss, J. (1981). Measuring delinquency. Beverly Hills, CA: Sage.

Hoeve, M., Blokland, A., Dubas, J. S., Loeber, R., Gerris, J. R., \& van der Laan, P. H. (2008). Trajectories of delinquency and parenting styles. Journal of Abnormal Child Psychology, 36(2), 223-235. doi:10.1007/s10802-007-9172-x.

Kass, R. E., \& Raftery, A. E. (1993). Bayes factors. Journal of the American Statistical Association, 90, 773-795. doi:10.2307/ 2291091.

Klein, M. W. (1989). Cross-national research in self-reported crime and delinquency. Dordrecht: Kluwer.

Koot, J. M., van den Oord, E. J., Verhulst, F. C., \& Boomsma, D. I. (1997). Behavioral and emotional problems in young preschoolers: cross-cultural testing of the validity of the Child Behavior Checklist/2-3. Journal of Abnormal Child Psychology, 23, 183-196. doi:10.1023/A:1025791814893.

Krug, E. G., Dahlberg, L. L., Mercy, J. A., Zwi, A. B., \& Lozano, R. (Eds.).(2002). World report on violence and health. Geneva: World Health Organization.

Lacourse, E., Cote, S., Nagin, D. S., Vitaro, F., Brendgen, M., \& Tremblay, R. E. (2002). A longitudinal-experimental approach to testing theories of antisocial behavior development. Development and Psychopathology, 14, 909-924. doi:10.1017/S0954579402004121.

Lacourse, E., Nagin, D. S., Vitaro, F., Côté, S., Arseneault, L., \& Tremblay, R. E. (2006). Prediction of early-onset deviant peer group affiliation: a 12-year longitudinal study. archives of General Psychiatry, 63, 562-568. doi:10.1001/archpsyc.63.5.562.

LeBlanc, M., \& Fréchette, M. (1989). Male criminal activity from childhood through youth: Multilevel and developmental perspective. New York, NY: Springer-Verlag.

Loeber, R., \& LeBlanc, M. (1990). Toward a developmental criminology. In M. Tonry, \& N. Morris (Eds.), Crime and justice: A review of research (pp. 375-473). Chicago: The University of Chicago press.

LeBlanc, M., \& McDuff, P. (1991). Activités délictueures, troubles de comportement et expérience familiale au cours de la laternce [Delinquency, behavior problems and family dynamics during the latency period]: Unpublished research report, School of Psycho-Education, University of Montreal.

Loeber, R., \& Hay, D. (1997). Key issues in the development of aggression and violence from childhood to early adulthood. Annual Review of Psychology, 48, 371-410. doi:10.1146/ annurev.psych.48.1.371.

Loeber, R., \& Stouthamer Loeber, M. (1998). Development of juvenile aggression and violence: some common misconceptions and controversies. The American Psychologist, 53, 242-259. doi:10.1037/0003-066X.53.2.242.

Loeber, R., Wung, P., Keenan, K., Giroux, B., Stouthamer-Loeber, M., Welmoet, B., et al. (1993). Developmental pathways in disruptive child behavior. Development and Psychopathology, 5, 103-133. doi:10.1017/S0954579400004296.

Loeber, R., Trembaly, R. E., Gagnon, C., \& Charlebois, P. (1989). Continuities and distance in disruptive boys' early fighting at school. Development and Psychopathology, 1, 39-50.

Moffitt, T. E. (1993). Adolescence-limited and life-course-persistent antisocial behavior: a developmental taxonomy. Psychological Review, 100, 674-701. doi:10.1037/0033-295X.100.4.674.

Moffitt, T. E., \& Caspi, A. (2001). Childhood predictors differentiate life-course persistent and adolescence-limited antisocial pathways 
among males and females. Development and Psychopathology, 13, 355-375. doi:10.1017/S0954579401002097.

Moffitt, T. E., Caspi, A., Dickson, N., Silva, P., \& Stanton, W. (1996). Childhood-onset versus adolescent-onset antisocial conduct problems in males: natural history from ages 3 years to 18 years. Development and Psychopathology, 8, 399-424.

Moffitt, T. E., Caspi, A., Rutter, M., \& Silva, P. A. (2001). Sex differences in antisocial behaviour: Conduct disorder, delinquency, and violence in the Dunedin Longitudinal Study. New York, NY: Cambridge University Press.

Moffitt, T. E., Caspi, A., Harrington, H., \& Milne, B. J. (2002). Males on the life-course-persistent and adolescence-limited antisocial pathways: follow-up at age 26 years. Development and Psychopathology, 14, 179-207. doi:10.1017/S095457940200 1104.

Muthén, B. (2004). Latent variable analysis: Growth mixture modeling and related techniques for longitudinal data. In D. Kaplan (Ed.), Handbook of quantitative methodology for the social sciences (pp. 345-368). Newbury Park, CA: Sage.

Muthén, L. K., \& Muthén, B. O. (1998). Mplus user's guide. Los Angeles: Author (2003).

Muthén, B. O., \& Shedden, K. (1999). Finite mixture modeling with mixture outcomes using the EM algorithm. Biometrics, 55, 463469. doi:10.1111/j.0006-341X.1999.00463.x.

Muthén, B., \& Muthén, L. K. (2000). Integrating person-centered and variable-centered analysis: growth mixture modeling with latent trajectory classes. Alcoholism, Clinical and Experimental Research, 24(6), 882-891. doi:10.1111/j.1530-0277.2000. tb02070.x.

Muthén, L. K., \& Muthén, B. O. (2007). Mplus user's guide. Fourth edition. Los Angeles, CA: Muthén \& Muthén (1998).

Nagin, D. S. (1999). Analyzing developmental trajectories: a semiparametric, group-based approach. Psychological Methods, 4, 139-177. doi:10.1037/1082-989X.4.2.139.

Nagin, D. S. (2005). Group-based modeling of development. Cambridge, MA: Harvard University Press.

Nagin, D. S., \& Tremblay, R. E. (1999). Trajectories of boys' physical aggression, opposition, and hyperactivity on the path to physically violent and nonviolent juvenile delinquency. Child Development, 70, 1181-1196. doi:10.1111/1467-8624.00086.

NICHD Early Child Care Research Network. (2004). Trajectories of physical aggression from toddlerhood to middle childhood (Vol. 69 Serial No. 278).

Nylund, K. L., Asparouhov, T., \& Muthen, B. (2007). Deciding on the number of classes in latent class analysis and growth mixture modeling. A Monte Carlo simulation study. Structural Equation Modeling, 14(4), 535-569.

Patterson, G. R., \& Yoerger, K. (1993). Developmental models for delinquent behavior. In S. Hodgins (Ed.), Mental disorders and crime (pp. 140-172). Newbury Park, CA: Sage.

Patterson, G. R., \& Yoerger, K. (1997). A developmental model for late-onset delinquency. In D. W. Osgood (Ed.), Motivation and delinquency. Nebraska symposium on motivation, vol. 44 (pp. 119177). Lincoln, NE: University of Nebraska Press.

Patterson, C. J., DeBaryshe, B. D., \& Ramsey, E. (1989). A developmental perspective on antisocial behavior. The Ameri- can Psychologist, 44, 329-335. doi:10.1037/0003-066X.44. 2.329 .

Patterson, G. R., Dishion, T. J., \& Yoerger, K. (2000). Adolescent growth in new forms of problem behavior: macro- and micropeer dynamics. Prevention Science, 1, 3-13. doi:10.1023/A: 1010019915400.

Schwartz, G. (1978). Estimating the dimension of a model. Annals of Statistics, 6, 461-464. doi:10.1214/aos/1176344136.

Silverthorn, P., \& Frick, P. J. (1999). Developmental pathways to antisocial behavior: the delayed-onset pathway in girls. Development and Psychopathology, 11, 101-126. doi:10.1017/ S0954579499001972.

Tolan, P. H., Gorman Smith, D., Huesmann, L., \& Zelli, A. (1997). Assessment of family relationship characteristics: a measure to explain risk for antisocial behavior and depression among urban youth. Psychological Assessment, 9, 212-223. doi:10.1037/10403590.9.3.212.

Tremblay, R. E. (2003). Why socialization fails: the case of chronic physical aggression. In B. B. Lahey, T. E. Moffitt, \& A. Caspi (Eds.), Causes of conduct disorder and juvenile delinquency (pp. 182-224). New York: The Guilford.

Tremblay, R. E. (2006). Prevention of youth violence: why not start at the beginning? Journal of Abnormal Child Psychology, 34(4), 481-487. doi:10.1007/s10802-006-9038-7.

Tremblay, R. E., Boulerice, B., Harden, P. W., McDuff, P., Pérusse, D., Pihl, R. O., et al. (1996). Do children in Canada become more aggressive as they approach adolescence? In Human Resources Development Canada \& Statistics Canada (Ed.), Growing up in Canada: National longitudinal survey of children and youth (pp. 127-137). Ottawa: Statistics Canada.

Tremblay, R. E., Nagin, D. S., Seguin, J. R., Zoccolillo, M., Zelazo, P. D., Boivin, M., et al. (2004). Physical aggression during early childhood: trajectories and predictors. Pediatrics, 114, e43-e50. doi:10.1542/peds.114.1.e43.

van Lier, P. A. C., Vitaro, F., Wanner, B., Vuijk, P., \& Crijnen, A. A. M. (2005). Gender differences in the developmental links between antisocial behavior, friends' antisocial behavior and peer rejection in childhood: results from two cultures. Child Development, 76, 841-855. doi:10.1111/j.1467-8624.2005.00881.x.

van Lier, P. A. C., Vitaro, F., \& Wanner, B. (2007). Onset of antisocial behavior, affiliation with deviant friends and childhood maladjustment: a test of the childhood and adolescent onset model. Development and Psychopathology, 19, 167-185. doi:10.1017/ S0954579407070095.

Vitaro, F., Brendgen, M., \& Barker, E. D. (2006). Subtypes of aggressive behaviors: a developmental perspective. International Journal of Behavioral Development, 30, 12-19. doi:10.1177/ 0165025406059968.

White, H. R., Bates, M. E., \& Buyske, S. (2001). Adolescence-limited versus persistent delinquency: extending Moffitt's hypothesis into adulthood. Journal of Abnormal Psychology, 110(4), 600 609. doi:10.1037/0021-843X.110.4.600.

Wiesner, M., \& Capaldi, D. M. (2003). Relations of childhood and adolescent factors to offending trajectories of young men. Journal of Research in Crime and Delinquency, 40, 231-262. doi:10.1177/0022427803253802. 